\title{
CONDICIONES DE PERSISTENCIA CAMPESINA Y DINÁMICA DEL AGRONEGOCIO EN EL NORTE DE LA PROVINCIA DE CÓRDOBA
}

\author{
Silvetti, F.1; Cáceres, D. ${ }^{2}$; Soto, G. ${ }^{3} \&$ Cabrol, D. ${ }^{4}$
}

\begin{abstract}
RESUMEN
El artículo analiza las condiciones de persistencia de campesinos resistentes al agronegocio en la provincia de Córdoba, comparando dos momentos históricos (2007 y 2015). Se consideró su acceso estratégico a recursos propios (capitales), las políticas públicas y los cambios en la dinámica del agronegocio en el territorio. La investigación incluyó la consulta a diversas fuentes y entrevistas a informantes clave. Se concluye que, con un éxito relativo, las estrategias individuales se rediseñan buscando la intensificación productiva y la pluriactividad. A nivel colectivo, se evidencia una participación decreciente de los campesinos en procesos organizacionales y la manifestación de conflictos internos por el acceso diferencial a recursos estatales.
\end{abstract}

Palabras clave: persistencia campesina, estrategias de resistencia, agronegocio, norte de Córdoba.

\begin{abstract}
Conditions of peasant persistence and dynamics of the agribusiness in the north of the province of Córdoba (Argentina).

The article analyzes the conditions of peasant persistence against agribusiness in the province of Córdoba, comparing two historical moments (2007 and 2015). Its strategic access to capital (capital), public policies and changes in agribusiness dynamics in the territory was considered. The
\end{abstract}

1.- Facultad de Ciencias Agrarias (FCA - UNC). Av. Valaparaíso s/n, Ciudad Universitaria. (5000) Córdoba, provincia de Córdoba. Email: felicitas.silvetti@gmail.com

2.- FCA - UNC / CONICET

3.- FCA - UNC

4.- CONICET

Manuscrito recibido el 3 de octubre de 2017 y aceptado para su publicación el 11 de diciembre de 2017.

Silvetti, F.; Cáceres, D.; Soto, G. \& Cabrol, D. Condiciones de persistencia campesina y dinámica del agronegocio en el norte de la provincia de Córdoba. FAVE - Ciencias Agrarias 17 (1): 57-70.

CC BY-NC-SA 4.0 c)(1) (3) 


\section{F. Silvetti et al.}

research included consulting various sources and interviewing key informants. It is concluded that, with relative success, individual strategies are redesigned looking for productive intensification and pluriactivity. At the collective level, there is a declining participation of peasants in organizational processes and the manifestation of internal conflicts due to the differential access to state resources.

Key words: peasant persistence, resistance strategies, agribusiness, Córdoba province.

\section{INTRODUCCIÓN}

El artículo analiza las condiciones de persistencia de unidades domésticas campesinas, ubicadas en el departamento Río Seco, en el norte de la provincia de Córdoba (Argentina). Se incluyen principalmente las estrategias de resistencia que comienzan a delinearse a comienzos del siglo XXI, cuando las condiciones de reproducción de los campesinos sufren una profunda crisis debido al avance del modelo del agronegocio en el territorio que provoca la descomposición de un número significativo de estos sistemas. A partir de la segunda década del siglo es posible identificar además un nuevo intento de readecuación de las estrategias campesinas vinculado a una reformulación de las estrategias tecnológicas productivas y de negocios de las empresas agropecuarias que actúan localmente.

Para algunos autores, la dinámica de expansión del capitalismo en el agro no es un proceso lineal o unívoco porque sus resultados son heterogéneos en función de las condiciones socioambientales locales y las asimetrías territoriales preexistentes $(4 ; 8$; 18 ). Bajo esta mirada, cobra relevancia preguntarse sobre cuáles son las condiciones para que algunas unidades domésticas campesinas logren adaptarse y persistir, hacia dónde dirigen sus inversiones de todo tipo y cuál es la naturaleza de las relaciones que mantienen entre ellas y con otros actores sociales en el territorio, en especial con el empresariado, a fin de defender el acceso y uso de recursos importantes para su reproducción social.

En la Argentina, la expansión del agronegocio como modelo socioproductivo dominante se produce en los últimos 20 años. Para Gras \& Hernández (2013) se basa en la incorporación de tecnología de punta y del conocimiento institucionalizado como pilares del modelo de negocios y articula una gran heterogeneidad de actores nacionales y transnacionales. Además establece fuertes vínculos entre el empresariado y otros ámbitos como el mediático, el académico y el político. Se vincula con la expansión de la frontera agropecuaria en relación al monocultivo de soja para exportación, que es manejado como una actividad extractiva con impactos ambientales y sociales negativos (24). El proceso de agriculturización va acompañado de una creciente intensificación de la actividad ganadera bovina, ligada a empresas que han incorporado nuevas pasturas, producción de granos para la alimentación animal y mejoras en la infraestructura productiva .

En el departamento Río Seco, como así también en el resto de los departamentos del arco noroeste de la Provincia de Córdoba, la transformación socioproductiva y ambiental que impulsa el modelo del agronegocio, ha sido notable a partir de comienzos del siglo XXI. Donde históricamente 
predominaba la producción familiar de tipo campesino centrada en la cría extensiva de bovinos y caprinos sobre una base de pasturas naturales y monte, se observa el ingreso de empresas que invierten en la producción de granos para exportación y en la ganadería intensiva (4).

El avance de la agricultura se tradujo en una importante homogenización del territorio que sigue la lógica de producción agroindustrial. El cultivo de oleaginosas anuales (en especial la soja) observa un crecimiento notable, pasando de ocupar sólo 745 ha en 1988, a 43.699 ha en 2002 (10; 11). Acompaña este crecimiento un marcado proceso de concentración económica que impacta en el número y tamaño de las explotaciones agropecuarias. Entre 1988 y 2002, las explotaciones de menos de 1.000 ha acusan una caída del $26 \%$, y se registra un incremento de la superficie promedio de los campos del 23\% (10; 11). El proceso va acompañado de una pérdida de importantes servicios ecosistémicos debido a la intensificación de las actividades de desmonte y la implantación de cultivos anuales para grano (9).

La nueva situación socioproductiva generó conflictos entre los campesinos y las empresas agropecuarias por el acceso a recursos clave y ocasionó que un número importante de unidades fueran "expulsadas" del medio rural hacia ciudades intermedias en condiciones de vida precarias. En particular, los campesinos se ven afectados por la reducción de las superficies de pastoreo para el ganado caprino, debido al cercamiento que producen los campos agrícolas (5). Se resiente igualmente el acceso a otros servicios ecosistémicos que provee el bosque nativo (e.g., leña y madera) y se deterioran las redes sociales locales, debido a la emigración campesina. Estas fueron algunas de las causas que provocaron una disminución acelerada del número de unidades campesinas en el territorio.

Es importante señalar que a pesar de la fuerte tendencia a la descomposición del sector campesino que se registró en los primeros años del siglo XXI, también es posible identificar unidades campesinas "resistentes" (CR). Investigaciones previas permitieron observar que los campesinos que lograban perdurar eran aquellos que disponían de mejores condiciones estructurales para desarrollar estrategias de inversión económica, y que mostraban una mayor habilidad para evaluar los cambios contextuales, identificar oportunidades y formular proyectos innovadores, con el fin de adaptarse a las nuevas condiciones socioambientales y productivas (7).

Sin embargo, la reconfiguración de las prácticas campesinas es limitada, ya que depende de cuestiones contextuales y estructurales que están fuera de su control. En este sentido, Cáceres (2014) considera que el poder de adaptación de los campesinos puede analizarse en torno a cinco dimensiones principales: i) el tipo o naturaleza del cambio que enfrentan los campesinos (e.g., económicos, climáticos, tecnológicos, sociales o políticos); ii) la magnitud espacial de los cambios y si éstos ocurren dentro o fuera de sus explotaciones; iii) la permanencia temporal de las transformaciones; iv) la velocidad a la que los cambios ocurren; y v) la trayectoria de las estrategias campesinas. Adicionalmente, la persistencia de los CR está vinculada con otras tres cuestiones: la naturaleza de la penetración capitalista, la organización campesina y el rol del Estado.

El presente artículo pretende entonces dar cuenta de las modificaciones que se observan en las condiciones de persistencia de 
los campesinos, expuestos a las rápidas y profundas transformaciones socioproductivas derivadas de la expansión del modelo de agronegocios en el norte de la provincia de Córdoba, focalizando centralmente en la reconfiguración de sus estrategias de reproducción social (6). Se propone identificar los cambios que registran estas estrategias, en el marco de sus trayectorias históricas. En particular, se prestará atención a sus estrategias de inversión en distintos tipos de capitales, identificar los factores causales y los compromisos o condicionamientos recíprocos entre distintos actores sociales que actúan en el mismo territorio. Igualmente creemos importante incluir en el análisis, el rol que juega el Estado a través de políticas específicas que habilitan las condiciones contextuales estratégicamente aprovechadas por los actores, según su disponibilidad de capital global y según el estado de las relaciones de fuerza que condiciona su poder de agencia.

\section{METODOLOGÍA}

El trabajo se ubica en el Departamento Río Seco, en el norte de la provincia de Córdoba (Argentina). El Departamento Río Seco $\left(6.754 \mathrm{Km}^{2}\right)$ tiene una forma irregularmente rectangular que se extiende en sentido Este-Oeste con una extensión máxima de $190 \mathrm{Km}$. El área correspondiente a la Llanura Extraserrana Oriental constituye la de mayor aptitud para la expansión de la frontera agrícola.
La investigación fue encarada como un estudio de caso desde un enfoque cualitativo, debido a la ausencia de datos estadísticos oficiales actualizados y comparables posteriores al Censo Nacional Agropecuario 2002. Como estrategia metodológica se buscó comparar el trabajo de campo realizado en dos momentos históricos. Por un lado, el realizado en 2007 en el marco de una investigación que buscaba comprender los procesos de descampesinización en el departamento Río Seco (7). En aquella oportunidad se realizaron 24 entrevistas (13 a campesinos "resistentes" y 11 a campesinos "expulsados" hacia poblaciones cercanas). La segunda etapa se realizó en 2015 para entrevistar a los 13 campesinos "resistentes" (pero sólo fue posible entrevistar a 11 de ellos) a fin de identificar cambios y continuidades en las estrategias implementadas desde 2007.

El relevamiento de la información se basó en: a) la revisión de fuentes bibliográficas y documentales; y b) la realización de encuestas y entrevistas en profundidad a los actores sociales clave vinculados con el problema de investigación a saber: i) 11 campesinos resistentes (en adelante CR); ii) técnicos pertenecientes al Instituto $\mathrm{Na}$ cional de Tecnología Agropecuaria (INTA), Ministerio de Agricultura y Ganadería de la provincia de Córdoba (MAGYA) y de la Secretaría de Agricultura Familiar de la Nación (SAF); y iii) técnicos y/o personal a cargo de unidades de tipo empresarial. 
RESULTADOS Y DISCUSIÓN

\section{1.- La trayectoria tecnológica productiva de las empresas agropecuarias en el departamento Río Seco. Cambios y continuidades}

La expansión del modelo del agronegocio en el norte de la provincia de Córdoba durante la primera década del siglo XXI se caracteriza por los siguientes aspectos: i) la transformación en el uso del suelo debido a la expansión del cultivo de soja y el desplazamiento de la ganadería tradicional (17; 21; ii) La expulsión por desposesión de una porción relevante de unidades campesinas hacia centros poblados intermedios (5); iii) una creciente deforestación (1); iv) una pérdida progresiva de la fertilidad como consecuencia de un uso más intensivo del suelo (21); iv) una modificación negativa del ciclo hidrológico del territorio (20); v) la concentración del control de los recursos por parte de empresas (15); y vi) la generación de nodos agroproductivos cuyos flujos se articulan sólo tangencialmente con las localidades cercanas, reforzando la lógica extractiva de la actividad agroindustrial de la región (20).

En cuanto a la trayectoria de las estrategias tecnológicas productivas de las empresas agropecuarias en el departamento Río Seco, es posible identificar dos momentos bien diferenciados correspondientes a la expansión agrícola, con una etapa inicial preparatoria de intensificación productiva.

Etapa preparatoria a la expansión agrícola: (1980-1995). A comienzos de la década de 1980 se manifiesta en el territorio una tendencia a la intensificación de la producción ganadera bovina mediante la remoción del monte nativo en áreas acotadas o parcelas y la implantación de maíz, sorgo y en algunos casos verdeos de invierno. Es- tas pasturas son destinadas a complementar la alimentación del ganado, basada fundamentalmente en pasturas naturales. En un momento posterior, se incorporan algunas pasturas megatérmicas perennes (principalmente gaton panic) para generar una oferta forrajera más estable. Estas transformaciones representan la primera etapa de intensificación productiva del departamento que sienta las bases para la futura expansión agrícola.

Primer momento de la expansión agrícola (1996-2010). Si bien esta etapa comienza con la aparición y el uso de semillas de soja transgénica en el norte de la provincia de Córdoba, se manifiesta con mayor claridad después de la devaluación monetaria de 2001. Se traduce en el corrimiento de la frontera agrícola en la región, el que se corresponde con el auge de la actividad sojera en el país. Según refirieron varios entrevistados, hacia el 2000 "la agricultura explotó" en el norte de la provincia. El avance de la frontera implicó la intensificación de la actividad de desmonte y el desplazamiento de campesinos y pequeños productores ganaderos principalmente impulsada por productores extraregionales.

El entusiasmo por avanzar con el cultivo de soja llevó a las empresas a no considerar suficientemente las condiciones socioambientales propias de esta región. Según los técnicos entrevistados, la estrategia del agronegocio en esta etapa puede ser caracterizada como "producir en cualquier campo a cualquier costo y a cualquier precio". Sin embargo, la escasa cobertura del suelo que deja el rastrojo de la soja, la elevada radiación solar propia de esta zona y algunos años continuos de sequía, se conjugaron para dejar en evidencia que se debían considerar las limitaciones del monocultivo de soja en el territorio. 
En paralelo a los problemas ambientales y productivos que genera la expansión sojera, se manifiestan importantes conflictos socioambientales entre las empresas y la población campesina. Los más significativos están vinculados con el acceso a la tierra, los efectos negativos sobre la salud de la población que generan las pulverizaciones con agrotóxicos, la emigración de la población y el debilitamiento del tejido social local (5).

Segundo momento de recuperación ganadera empresarial (desde 2010). Aquí se observa un desaceleramiento de la expansión agrícola, un avance del cultivo del maíz y un incremento de la producción ganadera intensiva y semi-intensiva. Estos cambios fueron impulsados por motivos fundamentalmente económicos. Gras y Cáceres (2017) señalan aquellos factores que influyen en la pérdida de rentabilidad de la agricultura durante este período: (i) la baja de los precios internacionales de la soja y el maíz; (ii) la pérdida de fertilidad de algunos suelos y la aparición de malezas resistentes que inciden en el rendimiento de los cultivos y en los costos directos; (iii) los elevados costos de flete para llevar los granos hasta el puerto de Rosario y; (iv) la política del gobierno argentino que, a fines de 2007, aumentó los derechos de exportación de soja y maíz. A este escenario económico adverso, se suma el impacto productivo generado por tres campañas productivas donde las precipitaciones estuvieron por debajo del promedio histórico (entre 2007 y 2010).

Estos factores, actuando en conjunto, influyeron para que algunas empresas reorientaran sus estrategias productivas, brindándole un rol más protagónico a la producción ganadera. Se observa entonces la instalación de feedlot (de ganado vacuno y/o porcino) en el territorio como una prác- tica productiva intensiva tendiente a evitar los elevados costos del flete a puerto y agregar valor en origen. Se advierte además que en paralelo a la creciente necesidad de convertir granos en carne, se incrementa progresivamente la presencia del maíz en la rotación agrícola hasta alcanzar un 50\% de maíz y $50 \%$ de soja. Además el hecho de que las retenciones a la exportación de soja se mantuvieran hasta 2015 en un valor alto y se hubiesen eliminado para el maíz, constituye un estímulo adicional.

\section{2.- La trayectoria de las estrategias de los campesinos resistentes. Continuidades y reformulaciones}

Las estrategias implementadas por las empresas agropecuarias implicaron una fuerte presión sobre los recursos productivos del territorio. En este marco, los CR han desarrollado estrategias tanto individuales como colectivas, tendientes a resistir esta presión. Las estrategias individuales, implican la puesta en juego del capital económico, social y cultural de las unidades domésticas (6), que es reorientado frente a la crisis de rentabilidad de las inversiones tradicionales desde principios del siglo XXI. Las estrategias colectivas, en cambio, se vinculan a la capacidad de organización y de movilización por parte de los campesinos de un conjunto heterogéneo de actores y recursos territoriales y extraterritoriales, con el fin de sumar fuerzas para poder mantener sus condiciones materiales de vida y hacer frente a los conflictos socioambientales suscitados por el avance de la frontera agropecuaria. Es importante señalar que ambas líneas de acción están vinculadas y se retroalimentan. 


\section{1.- Estrategias de resistencia individuales}

En la primera década del siglo XXI, los CR poseían una superficie predial relativamente mayor a la de los campesinos que fueron desplazados de sus campos y una dotación de recursos productivos que les permitía afrontar sus gastos cotidianos y realizar pequeñas inversiones. Mostraban también un perfil pluriactivo a fin de complementar los ingresos principales que obtenían de la producción agropecuaria. En 2007, los CR se manifestaron conformes con su modo de vida rural, y rechazaron la idea de vender o abandonar sus predios. También tenían proyectos productivos, los que buscaban introducir mejoras relacionadas principalmente con el aumento de la oferta forrajera. Esta forma de intensificación productiva facilitaría contrarrestar la reducción de la superficie de pastoreo que generaba la expansión agrícola y resistir mejor posicionados las presiones de las empresas sobre sus tierras $(5 ; 7)$.

Entre 2007 y 2015 se observan pocos cambios en las condiciones productivas de los CR entrevistados. La disponibilidad de superficie predial no ha variado sustancialmente, salvo en 1 caso que pasa de 43 ha a 11 ha, por sucesión y otro caso que compró 53 ha. Tampoco se identifican grandes cambios en sus existencias ganaderas. Sólo una unidad ha duplicado el número de caprinos, mientras que el resto ha mantenido o disminuido su número. A pesar de que en el 2007 los CR manifestaban interés en priorizar la producción bovina por sobre la caprina, tampoco se observa una mejora significativa en este rubro. Donde sí se observa cierto incremento es en la producción porcina (cuatro aumentan, uno disminuye y seis mantienen el mismo número de animales). Y también se constata un fuerte incre- mento en la cría de aves de corral (nueve tienen ahora más aves que en 2007). Se observan algunos cambios en relación a la estructura de las explotaciones. Entre 2007 y 2015 dos productores incorporan pasturas implantadas (1 ha y 19 ha), tres campesinos que tenían sus campos parcialmente cercados logran completar el cerco perimetral, y dos de ellos consiguieron cerrar una parcela dentro del campo (1 ha y 19 ha).

Estos datos ponen en evidencia que ante un escenario de "achicamiento" de los predios, los CR intentan la intensificación productiva a través de la implantación de pasturas megatérmicas, el desmonte manual selectivo para favorecer el crecimiento de especies forrajeras nativas, la suplementación del ganado en períodos críticos y la intensificación productiva de algunos rubros peridomésticos tradicionales tales como la cría de cerdos y aves de corral, orientados preferentemente hacia el mercado.

Paralelamente a la necesidad de intensificar la producción en los predios y transformar su perfil productivo, se advierte en las entrevistas un cambio significativo sobre la valoración inicialmente negativa que tenían los CR acerca de los alambres perimetrales que realizan las empresas. Frente al achicamiento del área de pastoreo y los conflictos suscitados por la invasión de los animales a los cultivos de soja y maíz, los campesinos prefieren limitar el número de caprinos porque éstos traspasan los alambrados con facilidad. Por lo tanto, plantean la necesidad de aumentar las existencias de ganado vacuno y para lograr este objetivo, el alambrado perimetral constituye una ventaja importante. De esta manera les resulta más accesible cerrar sus campos, cuando parte del alambrado es colocado y financiado por los empresarios agrícolas. 
Un problema que persiste sin embargo, es la necesidad de aumentar la oferta forrajera de los campos. Si bien algunos CR han logrado desmontar pequeñas parcelas o potreros para implantar pasturas, la mayoría aún no lo ha concretado, en parte por la falta de recursos económicos pero principalmente por el temor a las multas que establece la Secretaría Córdoba Ambiente frente a estos casos. En contraposición, observan que los productores agrícolas continúan desmontando sus predios porque "los empresarios pagan las multas y siguen adelante". Con frecuencia los campesinos tienen problemas para cumplimentar los requerimientos que ordena la Ley Provincial de Ordenamiento Territorial del Bosque Nativo (Ley 9814) tales como las dificultades para acreditar la tenencia de la tierra, la complejidad de los trámites administrativos y la necesidad de elaborar un plan de manejo de sus campos.

Llama la atención que, frente a la necesidad de rediseñar sus sistemas productivos y a la mayor conciencia sobre los obstáculos que enfrentan, algunos CR señalaron que el monte actualmente constituye un obstáculo que se opone a sus intereses y lo califican como "improductivo" o "eso que queda no sirve para nada". Esta perspectiva entra en contradicción con la alta dependencia que tienen los campesinos respecto a la diversidad de servicios ecosistémicos que ofrece el bosque nativo, con el rol que estos recursos ocupan en sus estrategias de reproducción social, y con el discurso colectivo que expresa la Unión Campesina del Norte de Córdoba (UCAN) y otras organizaciones campesinas.

Advertimos que la tendencia a una reorientación de la estrategia tecnológica productiva de las empresas hacia la ganadería intensiva y semi-intensiva (bovina y porcina) en base a granos y otros suplementos forrajeros, opera como una especie de "modelo" que orienta las estrategias de inversión económica campesina. Tanto los cerdos como los productos avícolas (pollos y huevos) están dirigidos actualmente hacia el mercado local, aunque es precisamente allí donde los CR enfrentan las mayores dificultades. Como se señala más arriba, la importancia creciente de la cría de porcinos y aves de corral en los predios campesinos, promueve la mercantilización productiva ya que estos no producen maíz. Pero, en paralelo, también desarrollan otras prácticas tendientes a aprovechar recursos provenientes de las explotaciones empresariales. Por ejemplo, recolectar (con o sin autorización de los propietarios) parte del maíz producido en los campos agrícolas, ya sea antes o después de la cosecha. A diferencia de lo que ocurre con la producción caprina que se realiza de manera extensiva a campo, para la cría de porcinos y aves se requiere de la construcción de instalaciones específicas y una asignación cotidiana de trabajo familiar mayor para atender a los animales. Además de la dependencia de maíz para su alimentación, también requieren de otros insumos externos tales como medicamentos o asistencia veterinaria (en particular los porcinos). Mientras la producción caprina y bovina, genera ingresos estacionales o esporádicos, la venta de lechones y huevos al mercado constituye una especie de "caja chica" para los campesinos, ya que va generando pequeños ingresos a lo largo de todo el año. Pero con frecuencia los campesinos enfrentan inconvenientes en la comercialización, particularmente en el caso de los porcinos debido a los controles que realiza el Servicio Nacional de Sanidad y Calidad Agroalimentaria. En consecuencia, se ven obligados a vender a intermediarios, 
o a arriesgarse a que le decomisen la carne cuando la trasladan a localidades vecinas para venderla en carnicerías, restaurantes o a particulares.

En este nuevo escenario productivo, crece la necesidad de dinero para poder acceder a materiales e insumos tales como postes, varillas y alambre para cercar potreros o corrales, herramientas agropecuarias para poder generar reservas alimenticias para el ganado, maquinaria agrícola para preparar la tierra y sembrar, semillas para implantar pasturas, chapas para techar corrales, compra de reproductores, suplementos alimenticios, etcétera. Parte de estas necesidades eran provistas en la primera década del siglo XXI, por el Programa Social Agropecuario en coordinación con otras entidades estatales tales como el INTA. Sin embargo, la administración grupal de estos recursos no resultó fácil para los campesinos, sino que por el contrario suscitó conflictos internos.

Los ingresos generados por las actividades productivas se complementan con la venta de servicios, el cobro de jubilaciones y pensiones. En cuanto a la venta de servicios, en el 2015 se agotaron las tareas que los campesinos realizaban vinculadas al proceso de agriculturización, tales como alambrado y destroncado. Ante la falta de esta alternativa, han aparecido otras alternativas laborales por cuenta propia novedosas como cortadero de ladrillos y servicio de fletes con vehículos precarios.

Es notoria en el territorio la extensión de pensiones y jubilaciones entre 2007 y 2015 , como así también los planes sociales que se promovieron durante el gobierno de Néstor Kirchner y Cristina Fernández, cubriendo con este beneficio al $90 \%$ de los CR. Si bien estas transferencias estatales hacia el sector favorecieron claramente la persistencia de los CR al contar con un ingreso fijo, algunos entrevistados consideran que en alguna medida la asistencia estatal ha desalentado la producción y la organización campesina. Se muestran por el contrario, más proclives a que el Estado les otorgue créditos blandos u otro tipo de ayudas para la producción.

Una condición importante que hace a la persistencia campesina, es la flexibilidad que le otorga la utilización de la mano de obra familiar, existiendo un consenso importante en la bibliografía sobre este tema $(12 ; 14 ; 18)$. Conscientes de la importancia de este factor, la mayoría de los CR ha manifestado su preocupación por la imposibilidad de garantizar el recambio generacional, ya que muchos jóvenes emigran por falta de oportunidades laborales y de capacitación en el territorio. Este no es un fenómeno nuevo, pero se ha acentuado en la última década, al reducirse significativamente la demanda de trabajo que requirió el proceso de agriculturización, vinculada al desmonte, destroncado y alambrado de los campos. Sin embargo, recientemente los CR advierten que la "vuelta a la ganadería" de algunas empresas está comenzando a generar demanda de personal y que existen ciertas iniciativas de capacitación dirigida a jóvenes, que puede contribuir a su retención. Esta cuestión es particularmente relevante en tanto las posibilidades de mantener la diversificación productiva de las economías campesinas, dependen directamente de la posibilidad de retener localmente la mano de obra familiar.

Otro aspecto que atenta sobre esta condición es la tendencia de los CR a reconvertir el capital económico por cultural. Los campesinos desde hace tiempo visualizan a la escuela como un medio de reproducción válido y por ello invierten en la educación de sus hijos más allá del nivel primario. 
En este sentido hemos constatado la capacitación e inserción laboral de hijos en el sistema de salud (enfermeras), de educación (maestros y profesores del nivel primario y secundario) y de seguridad (policías). Esta estrategia, que parecería ir a contrapelo con las posibilidades de incluir a las nuevas generaciones en las actividades productivas, no siempre genera su expulsión. Este es el caso por ejemplo, de los jóvenes que permanecen trabajando en su predio porque el jefe de familia sufre alguna discapacidad. Este ingreso extrapredial contribuye a la persistencia del conjunto del sistema y forma parte de la pluriinserción laboral que manifiestan los miembros de las unidades domésticas.

Estrategias de resistencia colectivas

Se trata de aquellas referidas a la comercialización, las redes sociales, y la organización. Las estrategias vinculadas a la comercialización se han focalizado en la idea de agregado de valor en origen, eliminación de intermediarios, y valorización de la calidad de la producción campesina. En relación a la capricultura, en tanto rubro tradicional orientado al mercado interno, han desarrollado acciones tendientes a generar valor agregado sobre la leche. Por iniciativa del gobierno de la Provincia de Córdoba, en la primera década del siglo XXI se creó la Cooperativa de Rayo Cortado, a fin de promover la industrialización local y venta de la leche caprina recolectada en una pequeña cuenca local. Dicha cooperativa funcionó con muchas dificultades financieras y operativas hasta el año 2013, cuando finalmente cerró sus puertas dejando una importante deuda y varios juicios laborales. Entre las dificultades que enfrentó, se destacan las dificultades gerenciales de su comisión directiva, para gestionar la cooperativa y desarrollar una carpeta de negocios que se pudiera sostener en el tiempo. Asimismo, los entrevistados destacan el escaso acompañamiento del emprendimiento por parte del gobierno provincial.

También se registran intentos de comercialización conjunta de productos campesinos con valor agregado, como por ejemplo queso de cabra o dulce de leche caprino. En estos casos fue la UCAN la que operó como promotora del proyecto. Según manifiestan los entrevistados estos intentos tuvieron escaso éxito y se sostuvieron por un plazo corto debido, principalmente, a problemas de gestión grupal del emprendimiento. Actualmente, los CR desarrollan estrategias de comercialización fundamentalmente individuales. Venden cabritos mamones a intermediarios y particulares y elaboran quesos y dulces que comercializan en localidades vecinas a particulares.

El proceso de cerramiento de los predios no sólo tiene implicancias productivas negativas para los CR sino también sociales y culturales, ya que dificulta o impide la comunicación tradicional entre los vecinos. La llegada de un actor social extraregional con mayor poder económico y político, con diferente enfoque productivo, y con distintas pautas culturales, modificó las características propias de la trama social local, promoviendo el desarrollo de otras redes de interacción que implican para los campesinos nuevas relaciones de subordinación:

(...) también hay como enfrentamientos entre los pequeños productores. Algunos que han hecho acuerdos con esta gente [los productores empresariales] y los que no. Algunos obtienen algunos beneficios, digamos, porque les tiran las sobras y ayudan a echar a los otros. Se habla entre ellos que 'tal productor' tiene los beneficios de que le aran, de 
que le han topado el campo, el agricultor le larga las sobras, les da la sojilla para los animales, alguna bolsa de maíz y con migajas los tiene comprados. A cambio de que el productor lo apoye, de que no le haga la contra, de que le cuide el campo porque él no viene... No hay arreglos explícitos ni escritos, son estrategias de sobrevivencia, ellos piensan que está bien lo que están haciendo. Son productores que están un poquito más arriba, a los que por ejemplo les hacen el saneamiento del título... (Técnico del PSA, 2007).

A principios del siglo XXI los conflictos se sitúan fundamentalmente en torno a la problemática de la tierra. A escala local, se observan dos manifestaciones del mismo problema: i) el aumento del precio de la tierra motivó a familiares que aún mantenían derechos sucesorios, a presionar a los residentes para que vendan la tierra a terceros; $y$ ii) las maniobras que realizaron empresarios para apropiarse de las tierras campesinas. A pesar de que la UCAN tuvo un rol destacado en la defensa de los derechos campesinos por la tierra, el avance del nuevo modelo ha sido muy importante. En tal sentido, pareciera no haber vuelta atrás en relación al proceso de remoción de monte, principal base forrajera de los caprinos, a lo que se suman el achicamiento de las áreas de pastoreo y la concentración empresarial de la tierra. Mientras los campesinos no puedan defender de una manera efectiva su acceso al bosque nativo, las bases sobre las que se asienta su reproducción social, se verán afectadas. Por otro lado, los predios campesinos continúan subdividiéndose por herencia y las fracciones que resultan, difícilmente soporten el recambio generacional. Además como ya señalamos más arriba, se advierte un desfa- saje entre el discurso individual de algunos campesinos en relación al bosque nativo y el discurso colectivo que se construye desde las organizaciones y se transmite trasciende hacia el resto de los sectores de la sociedad. En este marco se explica por qué el Movimiento Nacional Campesino Indígena (MNCI) intente avanzar más allá del reclamo por el acceso a la tierra, hacia una reforma agraria integral y reclame justicia ambiental. Esto incluye la discusión en torno a la superación de las limitaciones que presenta la propiedad privada, y coloca en el horizonte formas de tenencia comunitaria e igualitaria de los bienes comunes, tendientes a conformar una territorialidad campesina, entendida como control colectivo del espacio que excluye el extractivismo y la contaminación (2).

Cabe señalar que, a pesar de la importante intervención que tuvo la UCAN en la defensa de la tierra campesina (13), durante los últimos años sus acciones se han ido diluyendo en el departamento Río Seco respondiendo a una menor conflictividad por la tierra que se relaciona con otras cuestiones tales como: i) el hecho de que las tierras con mayor aptitud agrícola ya fueron ocupadas; ii) la baja en los precios de los commodities y la caída de la rentabilidad de la actividad; y iii) las restricciones al desmonte que impone la ley de bosques. Esto se pone en evidencia cuando los campesinos entrevistados manifiestan que ya no reciben ofertas para comprar o arrendar sus tierras y que el conflicto que existía en el pasado por la invasión del ganado caprino a los campos agrícolas, ya no es tan manifiesto ni relevante.

Existen programas estatales que han aportado recursos en el territorio. Destacamos el Programa Social Agropecuario (PSA) luego, Secretaría de Agricultura Familiar de la Nación (SAF), que opera hasta el año 2014, en que se retira el técnico a 
terreno. Este programa articula a su vez con diversos organismos, entre ellos la Agencia de Extensión Rural de INTA Cruz del Eje. Desde el gobierno de la provincia de Córdoba, el Ministerio de Agricultura plantea el programa "Mi Granja" que comenzó a implementarse en el año 2014 en el marco del Plan de Desarrollo de Noroeste. En conjunto, todos estos programas ofrecieron capacitación, asistencia técnica, y cuantiosos insumos y materiales para la producción (entre los que se cuentan por ejemplo, un equipo de labranza completo para uso grupal, 14 pantallas solares para alimentar un sistema de riego, materiales para mejorar o instalar corrales caprinos y gallineros). Sin embargo el trabajo de campo permitió observar que los recursos aportados entre 2003 y 2015 destinados a los campesinos no se han traducido en mejoras, que impacten de un modo significativo y sostenido en sus condiciones de vida. Esto pareciera ser válido tanto desde el punto de vista productivo como organizativo.

También algunos de los campesinos entrevistados, antes miembros activos de la UCAN, han dejado de participar en las actividades de la organización argumentando que tales compromisos les restaban mucho tiempo a sus tareas productivas. Actualmente los CR están demandando al Estado asistencia técnica pero de tipo individual y mayor acceso a servicios básicos para la zona tales como transporte, agua corriente, tendido eléctrico, mejoras en las viviendas $\mathrm{y}$ acceso a pensiones y jubilaciones.

La investigación permitió observar que, con frecuencia, los recursos aportados por los programas fueron capitalizados de manera preferencial por los CR mejor posicionados. Los entrevistados hacen referencia a conflictos grupales en torno a la administración de los recursos, falta de controles por parte de las instituciones acerca de la gestión efectiva de ellos, discontinuidad en la asistencia técnica de los programas y cambios bruscos en las políticas de intervención que terminaron generaron confusión entre los beneficiarios: "Yo estuve en el PSA que dieron mucha plata. Había 45 familias, se aprovecharon dos".

En relación a las estrategias colectivas de los CR se advierte que no estuvieron suficientemente articuladas a terreno y en algún punto competían o se interferían mutuamente. Las instituciones que las impulsaban parten de diagnósticos diferentes acerca del proceso global en curso, y/o de la situación particular que enfrentan los campesinos. Tampoco supieron visualizar y administrar los conflictos internos que se suscitaron en el grupo de CR y que promovió una apropiación diferencial de los recursos. Por otra parte, quienes impulsaron la "vía organización" no disponían de los recursos necesarios, o de suficiente capacidad técnica u operativa como para actuar eficazmente en ambos frentes.

\section{CONCLUSIONES}

El avance del modelo del agronegocio y el cambio en los patrones de uso del suelo en el norte de la provincia de Córdoba debilitaron las bases sobre las que se asienta la reproducción social campesina. La actividad más afectada es la capricultura que durante siglos estructuró el diseño de las explotaciones campesinas y su principal estrategia productiva. El cerramiento perimetral de los campos en la primera década del siglo XXI limitó las áreas de pastoreo, generó cambios en el diseño productivo de las explotaciones, favoreció la emigración campesina y debilitó sus redes sociales generando conflictos. 
Sin embargo, los resultados de este trabajo muestran que los sectores más vulnerables disponen de ciertos márgenes de maniobra para desarrollar estrategias novedosas. Los campesinos que presentan ciertas ventajas comparativas para persistir, rediseñan en la medida de sus posibilidades estrategias individuales y colectivas que obtienen un éxito relativo en relación a la dinámica cambiante del avance del capitalismo en el territorio y las políticas estatales. Algunos logran resistir en los momentos en donde tanto el mercado como el Estado incentivan a las empresas a crecer y aprovechan pequeñas oportunidades cuando el mercado agroalimentario se retrae. De esta manera combinan las ideas de intensificación productiva y diversificación de actividades. La intensificación productiva surge como una respuesta a las dificultades para acceder a los recursos forrajeros como consecuencia de las nuevas reglas que impone la expansión del modelo del agronegocio y la consecuente necesidad de incrementar la productividad de sus explotaciones. A su vez, la diversificación de actividades entendida en un sentido amplio, implica ampliar/reconvertir la base productiva de sus explotaciones y desarrollar una estrategia activa de búsqueda de nuevas opciones laborales que no responden a las actividades productivas tradicionales.

No obstante, ambas estrategias permitirán obtener un mayor volumen productivo, mejorar la calidad de la producción, u obtener artículos con mayor valor agregado, en la medida en que se renegocien las condiciones de articulación campesina con los mercados en los que participan y con los otros actores sociales con los que interactúan y con los cuales disputan la renta (3). De no ser así, el diferencial de ingreso producido como consecuencia de la generación de mayores volúmenes productivos y/o la mejora en la calidad de sus productos, resultará en una apropiación diferencial de los beneficios. En este sentido debemos advertir que el Estado, que debería contribuir a fortalecer la posición de los sectores más pobres y vulnerables, en tanto ente regulador de las relaciones económicas que tienen lugar entre actores sociales, actualmente sirve fundamentalmente a los intereses del sector económico dominante. Igualmente, los esfuerzos que promovieron la organización y participación de los campesinos, claves para su permanencia en el territorio, parecen hoy estar debilitados debido a conflictos internos pero también a la falta de continuidad de los programas estatales que en otros momentos los apoyaron.

\section{BIBLIOGRAFIA}

1- AGOST, L. 2015. Cambio de la cobertura arbórea de la provincia de Córdoba: análisis a nivel departamental y de localidad (período 2000-2012). Revista Facultad de Ciencias Exactas, Físicas y Naturales, 2 (2), 11-123

2- BARBETTA, P.; DOMÍNGUEZ, D. Y SABATINO, P. 2013. La persistencia de una incomodidad: repensando el campesinado en la Argentina. VII Jornadas Santiago Wallace de Investigación en Antropología Social. Sección de Antropologia Social. Instituto de Antropología. Facultad de Filosofía y Letras UBA, Buenos Aires, Disponible en: https://www.aacademica. org/000-063/322.pdf. Acceso 28/04/2016.

3- BEBBINGTON, A. 2012. Underground political ecologies: The second Annual Lecture of the Cultural and Political Ecology Specialty Group of The Association of American Geographers, Geoforum, 43, 1152-1162. 
F. Silvetti et al.

4- BENDINI, M.; STEIMBREGER, M. 13- ENSABELLA, B. Y ADAMO, S. 2012. Y PREDA, G. 2015. ¿Aceptación o resistencia campesina? Respuesta a la expansión del capital en tierras extrapampeanas, Revista Alternativa, 4, 1-30.

5- BISIO, C.; CÁCERES, D. M.; SILVETTI, F.; FERRER, G. Y SOTO, G. 2011. Los impactos de la agriculturización en el Norte de Córdoba. Descampesinización y persistencia. En López Castro, N. y Pividera, G. (comp.), Repensar la agricultura familiar. Aportes para desentrañar la complejidad agraria pampeana. Buenos Aires: Ediciones Ciccus.

6- BOURDIEU, P. 2007. Campo de Poder y Reproducción social. Elementos para un análisis de la dinámica de las clases. Córdoba: Ferreyra Editor.

7- CÁCERES, D. M.; FERRER, G.; SOTO, G.; SILVETTI, F. Y BISIO C. 2010. La expansión de la agricultura industrial en Argentina Central. Su impacto en las estrategias campesinas. Cuadernos de Desarrollo Rural, (7) 64: 91-119.

8- CÁCERES, D. M. 2014. Amenazas y desafíos que enfrenta el campesinado en Argentina ¿Descampesinización o persistencia? En Craviotti C. (comp.), Agricultura familiar en Latinoamérica. Buenos Aires: Ediciones Ciccus.

9- CÁCERES, D.M. 2015. Accumulation by Dispossession and Socio Environmental Conflicts Caused by the Expansion of Agribusiness in Argentina, Journal of Agrarian Change, 15 (1): 116-147

10- CNA. Censo Nacional Agropecuario. 1988. Instituto Nacional de Estadísticas y Censos de la República Argentina.

11- CNA. Censo Nacional Agropecuario. 2002. Instituto Nacional de Estadísticas y Censos de la República Argentina.

12- CRAVIOTTI, C. (comp.). 2014. Agricultura familiar en Latinoamérica. Continuidades, transformaciones y controversias, Buenos Aires: Ediciones Ciccus.

Resistir, organizarse, producir. Aportes para pensar la sustentabilidad social en comunidades rurales del norte cordobés. En Salomón, A. y Zarrilli, A. (comp.). Historia, política y gestión ambiental. Perspectivas y debates . Buenos Aires: Imago Mundi.

14-FEITO,M.C.2014. Ruralidades, agricultura familiarydesarrollo.BuenosAires:Ed.LaColmena.

15- GRAS, C. Y CÁCERES, D. M. 2017.

El acaparamiento de tierras como proceso dinámico. La estrategia de los actores en contexto de estancamiento económico. Población y Sociedad, 24 (2).

16- GRAS, C. Y HERNÁNDEZ, V. 2013. El agro como negocio. Producción, sociedad y territorios en la globalización. Buenos Aires: Editorial Biblos.

17- HOYOS, L. E., CINGOLANI, A. M., ZAK, M. R., VAIERETTI, M. V., GORIA, D. E. Y CABIDO, M. R. 2013. Deforestation and precipitation patterns in the arid Chaco forests of central Argentina. Applied Vegetation Science, 16 (2), 260-271.

18- LÓPEZ CASTRO, N. 2012. Persistencia en los márgenes. La agricultura familiar en el sudoeste bonaerense. Buenos Aires: Ediciones Ciccus. 19- LÓPEZ CASTRO, N. Y PRIVIDERA, G. 2011. Repensar la agricultura familiar. Aportes para desentrañar la complejidad agraria pampeana. Buenos Aires: Ediciones Ciccus.

20- SALIZZI, E. 2015. La expansión territorial agroindustrial: una aproximación al estudio de la frontera agraria moderna en el norte cordobés, Revista del Departamento de Geografía FFyH UNC, 3 (4): 40-65.

21- ZAK, M. R., CABIDO, M., CÁCERES, D. M. Y DÍAZ, S. 2008. What drives accelerate land cover change in central Argentina? Synergistic consequences of climatic, socio-economic and technological factors. Environmental Management, 42 (2), 181-189. 